\title{
Notes on the vocalizations of Northern Crombec (Sylvietta
} brachyura)

\section{Peter Boesman}

In the following we briefly analyze and compare voice of the three races of Northern Crombec (Sy/vietta brachyura). We also try to quantify the extent of any vocal differences using the criteria proposed by Tobias et al. (2010), as a support for taxonomic review. We have made use of sound recordings available on-line from Xeno Canto (XC).

Some examples of song from West to East:

\section{brachyura}

Senegal

D

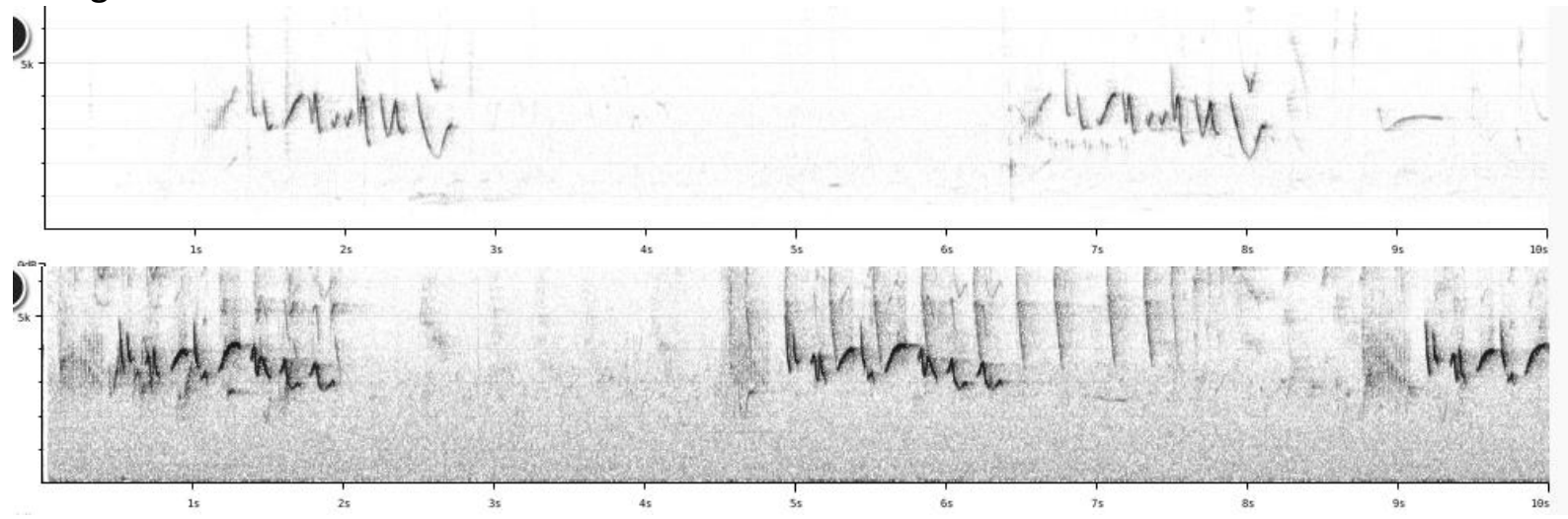

Ghana

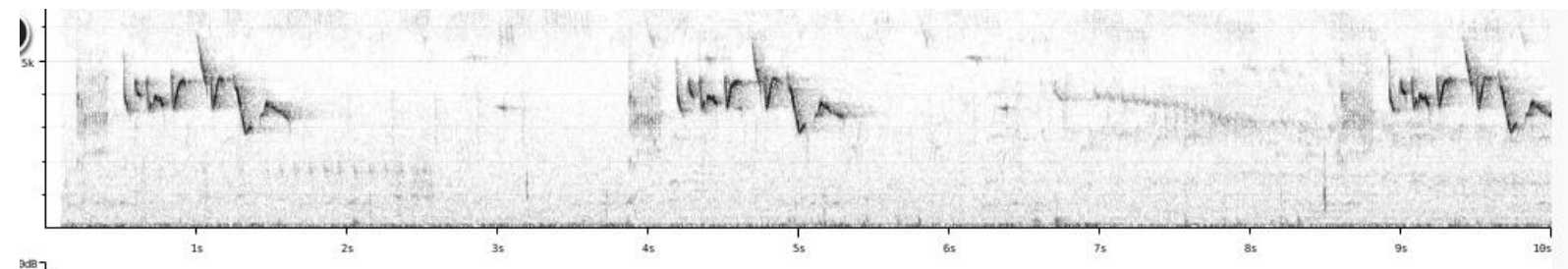

Burkina Faso

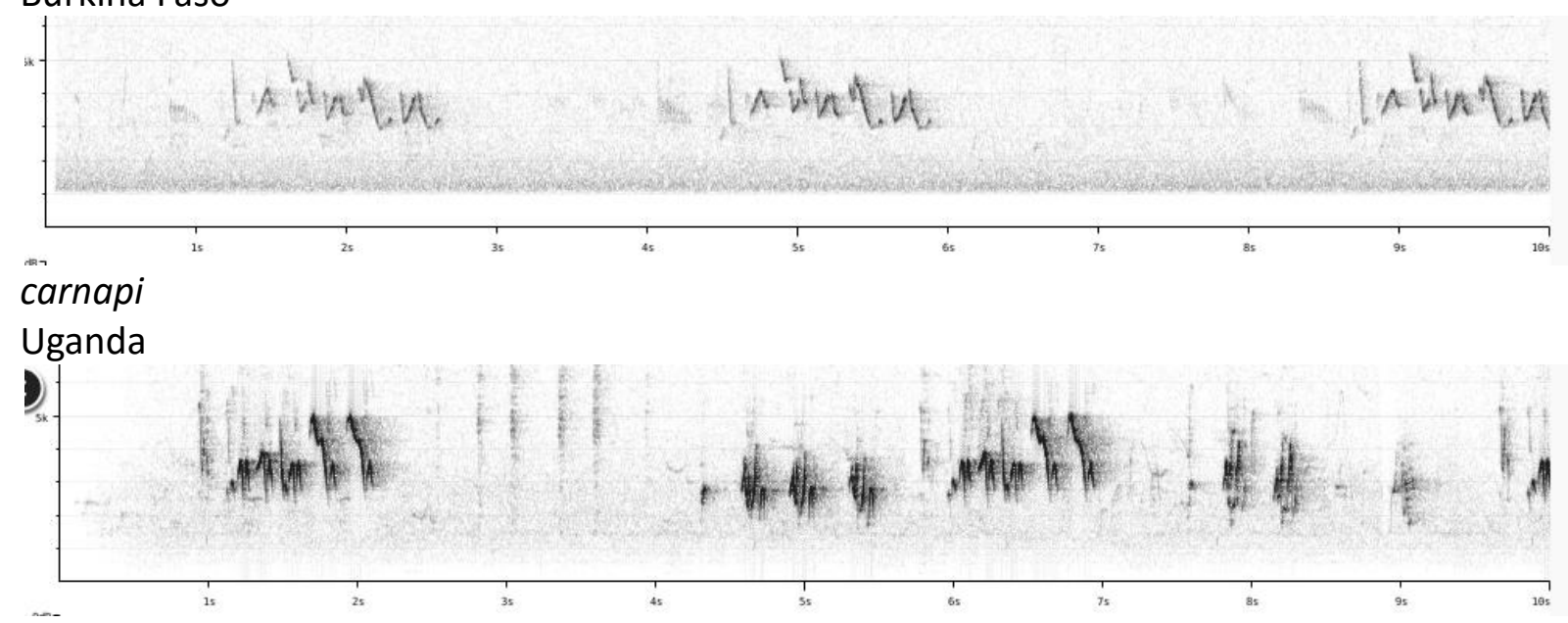



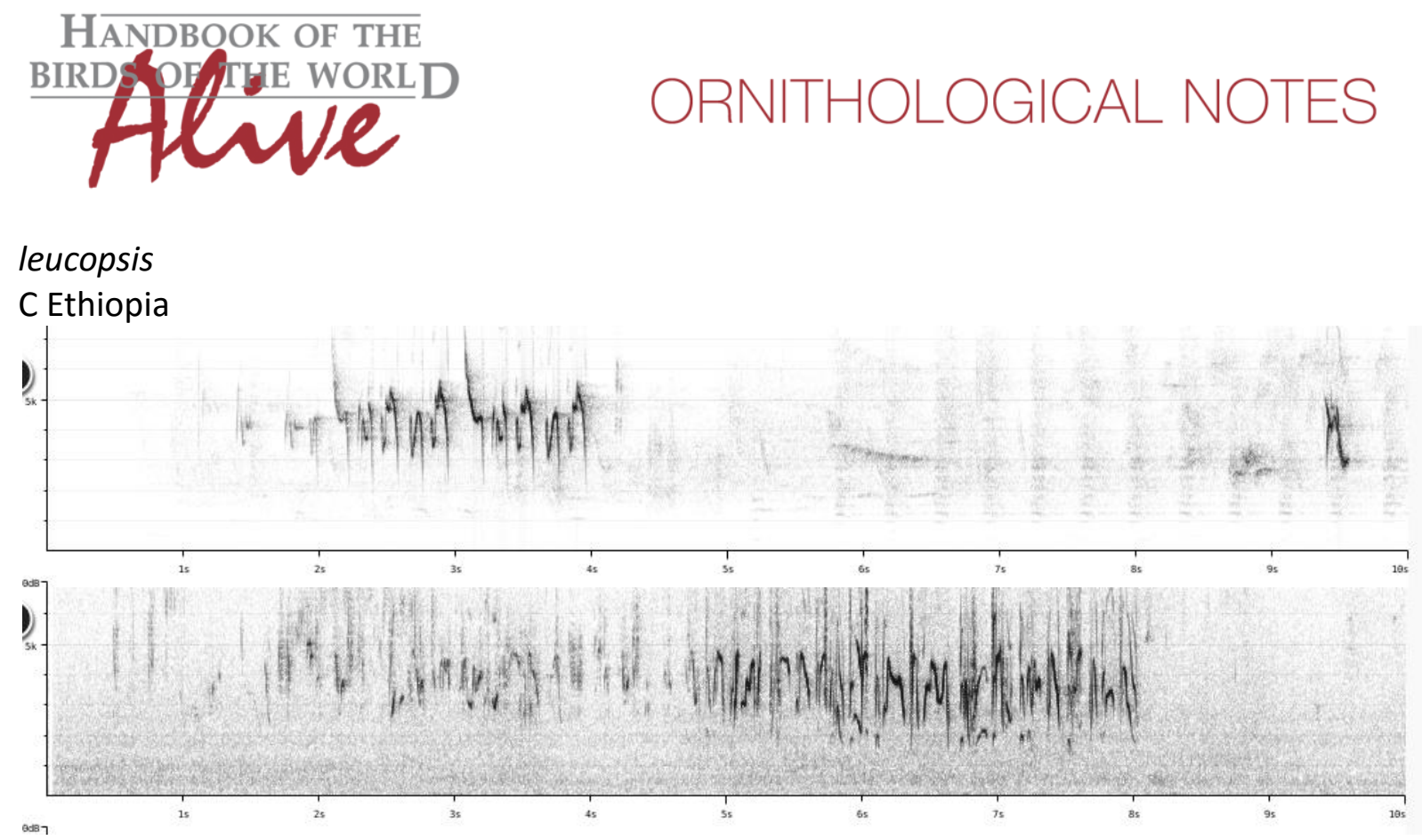

There is a clear difference in song between brachyura in West Africa and leucopsis. A single recording from Uganda (carnapi) is somewhat intermediate but closer to brachyura.

Unfortunately there are no other recordings of song from this central region.

Song of brachyura is sweet and mellow, versus rather piercing for leucopsis. This is quite clear also on the sonograms: notes in brachyura have a narrow frequency range (c.1-2kHz), most notes stay below $5 \mathrm{kHz}$ with exceptional peaks up to $6 \mathrm{kHz}$. On the contrary, most notes in leucopsis have a wide frequency range (c. $2-5 \mathrm{kHz}$ ), many go above $5 \mathrm{kHz}$ and some peaks up to $7-8 \mathrm{kHz}$. (Despite being less typical, the Uganda recording fits in the quantified criteria for brachyura).

We could thus score difference in song of brachyura/carnapi vs. leucopsis based on the latter's higher max. frequency (2) and larger frequency range (2). Assuming these are independent variables, this would lead to a total vocal score of 4 when applying Tobias criteria.

This note was finalized on 8th February 2016, using sound recordings available on-line at that moment. We would like to thank in particular the sound recordists who placed their recordings for this species on XC: Peter Boesman, Phil Gregory, Steve Hampton, Gabriel Jamie, Antero Lindholm, David Moyer, Bram Piot, Andrew Spencer and Martin St-Michel.

\section{References}

Tobias, J.A., Seddon, N., Spottiswoode, C.N., Pilgrim, J.D., Fishpool, L.D.C. \& Collar, N.J. (2010). Quantitative criteria for species delimitation. Ibis 152(4): 724-746.

\section{Recommended citation}

Boesman, P. (2016). Notes on the vocalizations of Northern Crombec (Sylvietta brachyura). HBW Alive Ornithological Note 220. In: Handbook of the Birds of the World Alive. Lynx Edicions, Barcelona. (retrieved from http://www.hbw.com/node/932178 on 7 September 2016). 